\title{
Pengamatan Seismisitas Gempa Bumi Di Wilayah Pulau Sulawesi Menggunakan Perubahan Nilai a-b
}

\author{
Guntur Pasaua*, Ferdya, Gerald H. Tamuntuana \\ aJurusan Fisika, FMIPA, Unsrat, Manado
}

\begin{tabular}{l} 
K A T A K U N C I \\
\hline seismicitas, \\
Nilai a-b \\
Maximum likelihood \\
Periode ulang
\end{tabular}

\begin{abstract}
A B S TR A K
Telah dilakukan pengamatan seismicitas gempa bumi Pulau Sulawesi berdasarkan perubahan nilai $a-b$. Pulau Sulawesi yang merupakan wilayah pertemuan beberapa lempeng bumi memiliki aktivitas kegempaan yang sangat tinggi sehingga diperlukan upaya mitigasi terhadap ancaman gempa bumi tersebut. Salah satu upaya mitigasi adalah memetakan paramaeter seismotektonik yakni nilai $a-b$ secara spasial. Penentuan variasi perubahan nilai parameter seismotektonik menggunakan metode statistik maximum likelihood. Data yang digunakan adalah data hypocenter gempa yang dikumpulkan dari dua katalog yakni data USGS dan ANSS selama selang pengamatan Februari 1963 sampai Mei 2016 meliputi wilayah $18^{\circ} \mathrm{BT}-127^{\circ} \mathrm{BT}$ dan $7^{\circ} \mathrm{LS}-5^{\circ} \mathrm{LU}$. Hasil analisis perubahan nilai parameter seimotektonik secara umum menunjukkan bahwa variasi nilai $b$ berkisar 0.55-2.55, dan nilai a berkisar 3.72-14.75. Dari hasil analisis periode ulang secara umum menunjukkan bahwa periode ulang gempa magnitude 6.0 sekitar 2.4-12 tahun magnitude, magnitude 6.5 sekitar 6-30 tahun, magnitude 7.0 sekitar 14-70 tahun, gempa dengan magnitudo 7.5 sekitar 32-162.5 tahun.
\end{abstract}

\section{K E YW O R D S}

Seismicity,

a-b value,

Maximum likelihood,

Return period
A B S T R A C T

The earthquake seismic activity in Sulawesi Island based on changes in the a-bvalue has been observed. Sulawesi Island which is the junction of several tectonic plates, has a very high seismic activity so it is crucial to mitigate the thread of the earthquake. One effort to mitigate the earthquake is by measuring and mapping the value of this abseismotectonicparameter spatially. Maximum likelihood statistical methods has been employed todetermine thechanges of parameter seismotectonic variationvalue. The datas used in this research is the observatory earthquake hypocenter data catalog which is USGS data and ANSS datacollected fromFebruary 1963 until May 2016 covering an area $118^{\circ} \mathrm{E}-127^{\circ} \mathrm{ELongitude}$ and $-7^{\circ} \mathrm{S}-5^{\circ} \mathrm{NL}$ atitude. The results of the analysis of changes in the parameter seimotektonicvaluegenerally indicates that the variations in the value of $b$ ranges from $0: 55$ to $2: 55$, and the value of a range from 3.72 to 14.75 . Based on analysis, the return period of 6.0 earthquake magnitude generally are around 2.4 to 12 years, the return periodof 6.5 magnitude are around 6 to 30 years, the return periodof 7.0 magnitude are around 14 to 70 years, the return period of 7.5 magnitude earthquakeare around 32.5 to 162.5 years.

\begin{tabular}{l}
\hline TERSEDIA ONLINE \\
\hline 1 Februari 2017 \\
\hline
\end{tabular}

1. Pendahuluan

Pulau Sulawesi secara geologis diyakini oleh para ahli kebumian terletak pada pertemuan empat lempeng (complex junction) utama dunia yaitu lempeng Eurasia, lempeng Indo-Australia, lempeng Pasifik dan satu lempeng mikro yaitu lempeng Laut Filipina. Akibat tekanan dari pergerakan lempeng-

*Corresponding author: Jurusan Fisika FMIPA UNSRAT, Jl. Kampus Unsrat, Manado, Indonesia 95115; Email address: pasaujunior@gmail.com Published by FMIPA UNSRAT (2017) 
lempeng tersebut menyebabkan interior lempeng bumi dari kepulauan Sulawesi terpecah-pecah menjadi empat lengan yakni lengan selatan, lengan tenggara, lengan timur dan lengan utara yang menyerupai huruf $K \quad[3,5]$. Pulau Sulawesi merupakan pusat benturan keempat lempeng kerak bumi.Pulau ini seakan dirobek oleh berbagai patahan (faulting) dan sesar (thrusting) dimana berbagai jenis batuan tercampur sehingga posisi stratigrafinya menjadi sangat rumit (Gambar 1). Dampak dari benturan antar lempeng kerak bumi yang berbeda jenis tersebut menimbulkan terjadinya penimbunan energi (stress energy) sehingga dalam kurun waktu tertentu akan dilepaskan secara tibatiba dalam bentuk gempa bumi dengan nilai besaran gempa yang beragam [4].

Dampak dari kondisi tektonik ini sehingga mengakibatkan Pulau Sulawesi menjadi wilayah yang sangat rawan bencana alam kebumian khususnya bencana gempa bumi. Beberapa gempa besar yang pernah terjadi di wilayah ini misalnya pada zona kompresi Banggai terjadi tahun 2000 (Mw7.6). Di sepanjang Sesar Palukoro tercatat sebanyak 4 kali gempa dengan kekuatan lebih besar dari M7.0 dalam kurun waktu dua ratus tahun terakhir, termasuk gempa Palu tahun 1938 (M7.9) dan gempa di bagian barat lengan Sulawesi utara pada tahun 1996 (M7.9). Selain di daratan Sulawesi juga mempunyai sumber gempabumi di bawah laut, yakni dari zona subduksi Sulawesi utara.Di zona subduksi ini tercatat kejadian gempa berpotensi tsunami pada tahun 1904 (Mw 8.4).Sulwesi Selatan juga tidak luput dari bencana gempa dan tsunami.Di wilayah ini sumber gempa berada di daerah pantai barat dan juga di selatan Makasar.Gempa tahun 1969 (M6.9) dan tahun 1984(M6.6) menyebabkan ratusan korban jiwa di Kabupaten Majene dan Mamuju.Kemudian tahun 1820, gempa disertai tsunami memporakporandakan wilayah Kota Makassar.

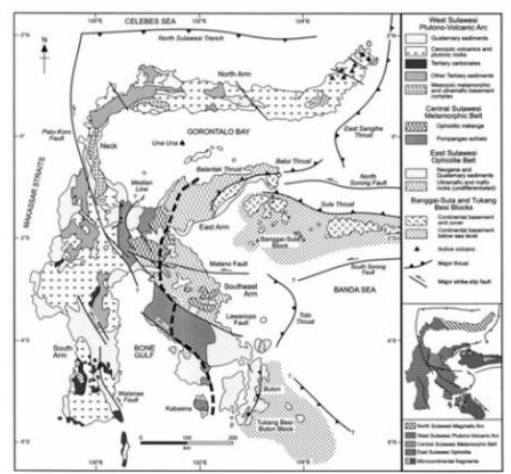

Gambar 1.Peta tektonik Pulau Sulawesi (Hall dan Wilson, 2000).

Upaya mitigasi gempa bumi perlu dilakukan untuk memperkecil dampak dari bencana gempagempa tersebut.Salah satu upaya mitigasi adalah melakukan pemetaan parameter seismotektonik yakni nilai $b$ dan nilai a secara spasial untuk untuk memetakan wilayah rawan gempa dan memprediksi periode ulang gempa bumi di wilayah ini.Nilai a secara fisis menunjukkan tingkat seismicitas di suatu wilayah sedangkan nilai $b$ mencerminkan aktivitas stress lokal dan heterogenitas struktur suatu wilayah. Secara statistik perubahan nilai-b yang signifikan telah teramati di beberapa zona subduksi lempeng, di sepanjang zona patahan dan di zona aftershock [6].

Metode yang digunakan untuk menentukan nilai parameter seismotektonik disuatu wilayah dikenal dengan relasi Gutenberg-Richter. Relasi ini menyatakan bahwa frekuensi atau jumlah gempa bumi adalah merupakan karakteristik basis dari aktifitas seismik di suatu daerah selama selang waktu tertentu. Metode Least Square atau model Guttenberg-Ricter [2], frekuensi terjadinya gempa dengan magnitudo $M \geq m$ persatuan waktu, menurun secara ekponensial dengan meningkatnya magnitudo gempa (Gambar 2). Hubungan tersebut dapat dinyatakan sebagai berikut:

$$
\log N(M)=a-b M
$$

Dengan: $N(M)$ adalah jumlah gempabumi dengan magnitudo lebih besar atau sama dengan M. Nilai-a merupakan parameter seismik yang menunjukkan tingkat aktivitas kegempaan dan besarnya bergantung pada periode observasi dan luas wilayah. Nilai-b merupakan parameter tektonik, nilai b biasanya mendekati 1 dan menunjukkan potensi relatif dari gempabumi besar dan gempabumi kecil [6].

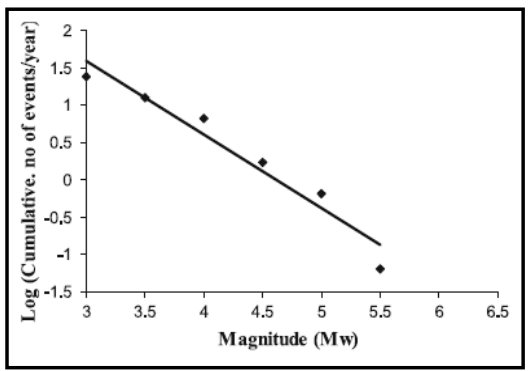

Gambar 2.Distribusi magnitudo GuttenbergRichter (Baker, 2008).

Nilai $a$ dan $b$ ditentukan berdasarkan data yang dikelompokkan dari beberapa area ke dalam sekelompok data dengan analisa statistik model maximum likelihood. Estimasi parameter $a$ dan $b$ menggunakan analisa statistik model maximum likelihood, memberikan hasil yang lebih stabil karena memodelkan kemiringan garis bukan dari hasil fitting least square tiap magnitudo, tapi kemiringan nilai tengah (mean) magnitudo fungsi distribusi Gaussian. Dalam metode likelihood [8], nilai a dan b dapat diperoleh dari persamaan:

$$
b=\frac{\log e}{\bar{M}-M \min }=\frac{0.4343}{\bar{M}-M \min }
$$

Standar deviasi dari nilai-b dapat ditentukan menggunakan formula dari Shi dan Bold (1982) sebagai berikut :

$$
\delta b=2.30 b^{2} \sqrt{\sum_{i=1}^{n} h_{i}-\bar{M}^{2} / n(n-1)}
$$

Sedangkan nilai a diperoleh dari rumusan: 


$$
a=\log N\left(M \geq M_{0}\right)+\log (b \ln 10)+M_{0} b
$$

Kemungkinan terjadinya satu kali atau lebih gempa dengan magnitude $\geq$ Mo dalam periode $\mathrm{T}$ adalah:

$$
P(M, T)=\left(1-e^{-N(M) \bullet T}\right)
$$

Kemungkinan waktu terjadinya kembali (periode ulang ) gempa bumi dengan magnitudo $\mathrm{M}$ adalah:

$$
\theta=\frac{1}{N_{1}(M)} \text { tahun }
$$

\section{Material dan Metode}

Data yang digunakan dalam penelitian ini adalah data-data gempa yang pernah terjadi di wilayah Sulawesi dan sekitarnya. Data yang dikumpulkan dari dua sumber katalog yakni NEICUSGS dan ANSS selama periode pengamatan dari tahun Februari 1963-Mei 2016. Jumlah data yang dihimpun sebanyak 11.955 data dengan magnitudo terkecil M3.6 dan magnitudo terbesar M7.9 serta kedalaman minimum sebsar $0.9 \mathrm{~km}$ dan terdalam sebesar $675.1 \mathrm{~km}$. Data-data gempa yang telah dikumpulkan dari berbagai katalog mempunyai skala magnitudo yang berbeda-beda, oleh karena itu maka langkah pertama yang harus dilakukan adalah menyeragamkan skala magnitudo ke dalam skala momen magnitude Mw. Hasil penyeragaman kemudian disortir untuk menentukan gempa independent (mainshock) lepas dari gempa dependent seperti foresock dan aftersock. Proses penyeragaman ini dilakukan dengan menerapkan kriteria time window dan distance window menggunakan metode empiris yang diusulkan oleh Gardner \& Knopof [1]. Langkah selanjutnya menentukan kelengkapan magnitude ( Magnitude of Completeness [Mc]). Kemudian memetakan nilai $a-b$ secara spasial untuk menentukan nilai parameter seismotektonik.

Penentuan parameter nilai-a dan nilai- $b$ dalam penelitian ini menggunakan metode maximum likelihood dengan Mc dipilih yaitu kombinasi terbaik (Mc 95\% probability - Mc 90\% probability maximum curvature). Untuk memetakan nilai $b$ secara spasial, wilayah penelitian dibagi menjadi grid-grid dengan ukuran $0,1^{\circ} \times 0,1^{\circ}$ sehingga wilayah penelitian ini sebanyak 10.710 jumlah grid. Nilai- $b$ dihitung untuk tiap titik grid dalam radius konstan yang mengandung 50 event.Untuk mendapatkan nilai-b antara titik-titik grid digunakan interpolasi spline.Nilai- $b$ yang mewakili masingmasing titik adalah nilai-b yang tingkat kepercayaannya (goodness of fit) lebih dari $90 \%$ [10].

\section{Hasil dan Pembahasan}

Data gempa yang digunakan adalah data hypocenter dari tahun 1963-Mei 2016 seperti di tampilkan pada gambar 3 berikut:

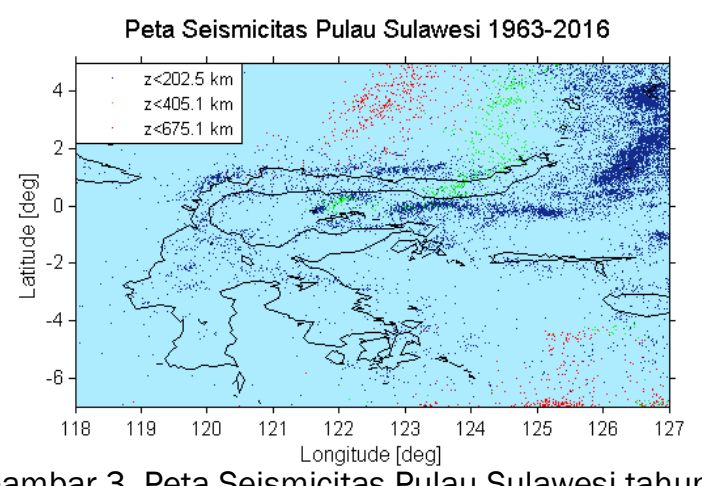

Gambar 3. Peta Seismicitas Pulau Sulawesi tahun 1963-2016

Dari plot hypocentergempa diatas menunjukkan bahwa Pulau Sulawesi telah dilanda ribuan kali gempa mulai dari gempa kecil sampai besar. Wilayah yang mempunyai aktivitas kegempaan yang tinggi umumnya berada pada wilayah lengan utara mulai dari barat sampai ke timur.Sementara wilayah lengan timur dan tenggara mempunya aktivitas yang sedang, sedangkan wilayah lengan selatan menunjukkan aktivitas gempa yang relativ rendah dibanding dengan wilayah lainnya kecuali bagian utara yakni Mamuju sampai Palu.

Dari jumlah data gempa yakni sebanyak 11.955 gempa yang termasuk dalam gempa dependent sebanyak 9233 atau $77,23 \%$, sisanya menjadi gempa independent sebanyak 2.722 buah data. Dari data yang tersisa kemudian dilakuan proses kelengkapan magnitude $M c$ (magnitude completeness/Mc). Dari distribusi frekuensimagnitudo gempa menunjukkan bahwa nilai $M c$ sekitar 4.9 dengan nilai $b$ sekitar $0.932 \pm 0.02$ dan nilai a sekitar 6.13 (Gambar 4). Nilai Mc ini 4.9 menunjukkan bahwa jaringan seismograf yang ada hanya mampu merekam gempabumi pada magnitudo tersebut dengan baik.

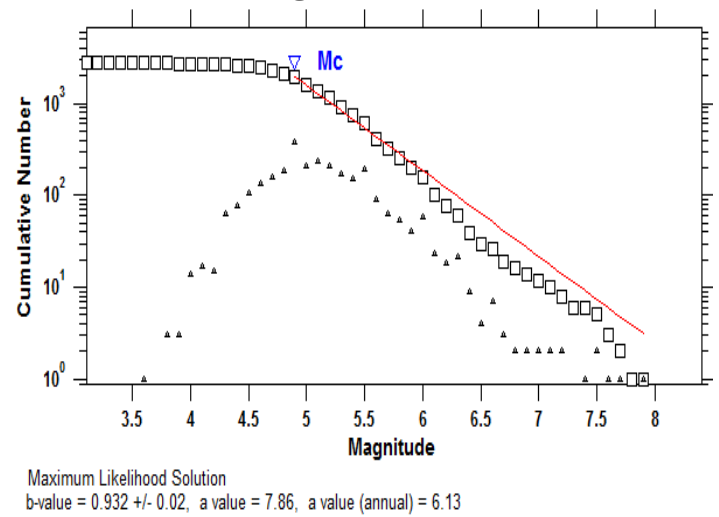

Magnitude of Completeness $=4.9$

Gambar 4. Distribusi Frekuensi-Magnitudo

Pulau Sulawesi tahun 1963-2016

Nilai parameter seismotektonik yakni nilai $b$ dan nilai a secara spasial seperti ditunjukkan pada Gambar 5.Secara umum dari nilai $b$ berkisar antara 0.55 sampai 2.55 (Gambar 5).Sedangkan nilai a berkisar antara 3.72 sampai 14.75 (Gambar 6). 


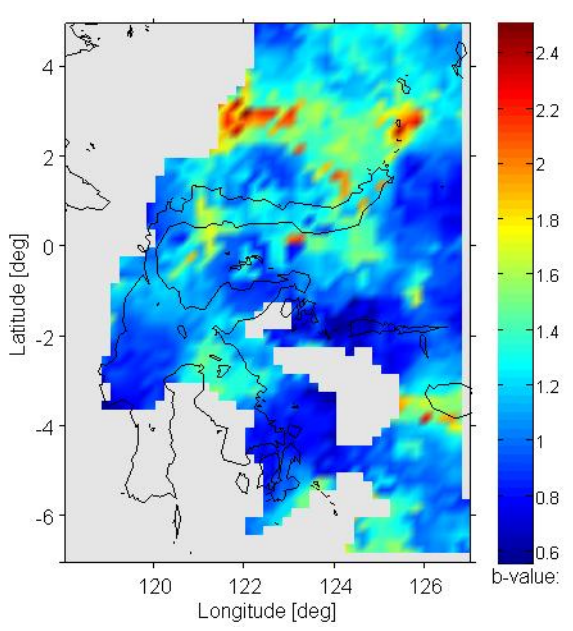

Gambar 5. Peta Variasi Nilai $b$

Nilai-b yang rendah yakni sekitar 0.55 terjadi di wilayah Sulawesi Tenggara bagian selatan (Kendari, Konawe, Pulau Wowoni, Buton dan Muna), wilayah Sulawesi Barat (Polewali, Mamasa, Majene dan Mamuju) dan Wilayah lengan utara yakni sekitar Laut Maluku. Nilai $b$ yang rendah ini biasanya berkorelasi dengan tingkat stress yang tinggi. Nilai $b$ yang rendah ini juga menunjukkan bahwa kemungkinan besar terjadi gempa-gempa sedang sampai besar sangat mungkin karena tingkat stressnya yang tinggi.Sebaliknya nilai $b$ yang tinggi ( $b \sim 2.4)$ ditemukan sekitar Laut Sulawesi yang biasanya berkorelasi dengan struktur yang makin tidak homogen.Selain itu nilai $b$ yang tinggi menurut beberapa ahli berkorelasi dengan titik-titik api/titik leleh (meltingpoint) yang merupakan daerah geothermal (Wandono, 2004).

Dari variasi nilai a secara spasial pada Gambar 6 didibawah menunjukkan bahwa nilai a di wilayah Sulawesi berkisar 3,73 sampai 14,75. Nilai a yang tinggi ini mengindikasikan bahwa wilayah ini memiliki keaktivan gempa yang sangat tinggi [6], nilai a yang tinggi ini diketemukan sekitar laut Sulawesi.

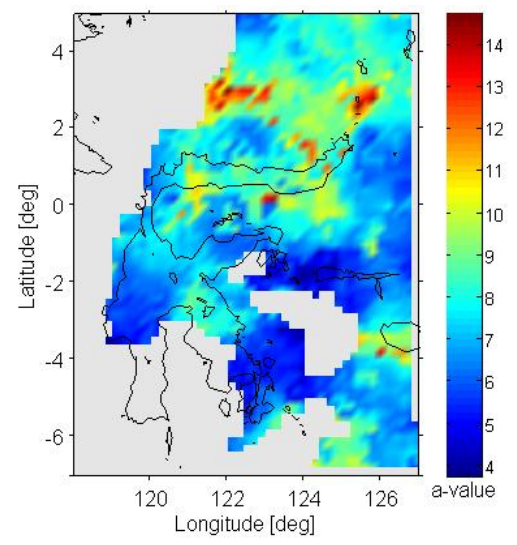

Gambar 6. Peta Variasi Nilai a

Periode ulang gempa di Pulau Sulawesi secara umum sangat bervariasi seperti yang ditunjukkan pada Gambar 7 dan Gambar 8 dibawah. Pada Gambar 7 menunjukkan bahwa periode ulang gempa dengan magnitude M6.0 memiliki periode ulang bervariasi mulai dari 2.4 tahun sampai 12 tahun dengan wilayah-wilayah yang berperiode pendek umumnya berada di sepanjang lengan utara Sulawesidan laut Maluku. Gempa dengan magnitudo M6.5 mempunyai periode ulang mulai dari 6 sampai 30 tahun (Gambar 7b) dengan periode pendek terjadi disekitar teluk Tomini dan laut Maluku.
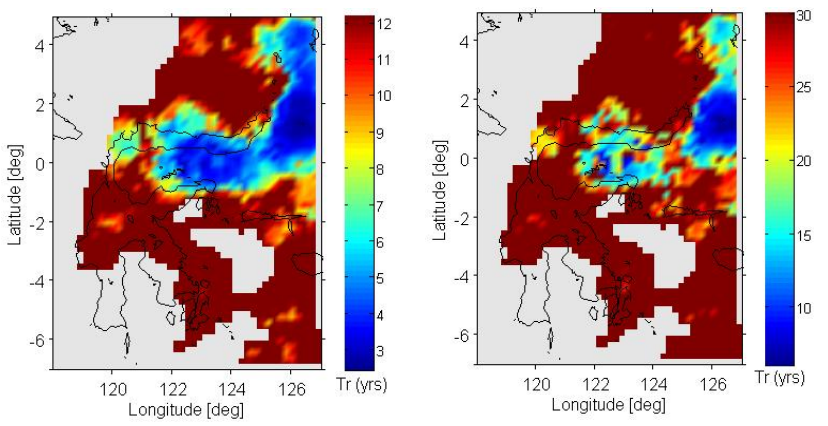

(a)

(b)

Gambar 7. Periode Ulang Gempa Bumi (a) Magnitudo 6.0 (b) Magnitudo 6.5
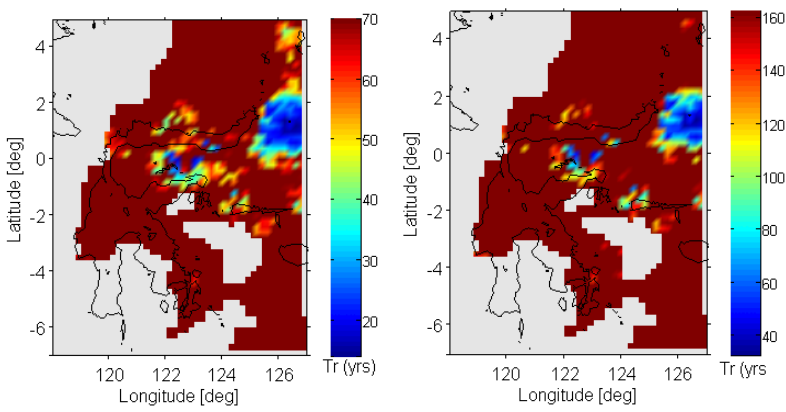

(a) (b)

Gambar 8. Periode Ulang Gempa Bumi (a) Magnitudo 7.0 (b) Magnitudo 7.5

Gempa dengan magnitude M7.0 memiliki periode ulang 14 sampai 70 tahun (Gambar 8a).Sedangkan gempa dengan magnitdo M7.5 (Gambar 8b) memiliki periode ulang sekitar 36 sampai 162 tahundengan periode pendek kemungkinan akanterjadi disekitar laut Maluku.Kemungkinan terjadinya suatu gempa kembali pada periode pendek dari suatu gempa sangat berkorelasi dengan nilai parameter.a-byang tinggi.

Dari beberapa plot periode ulang pada berbabagai magnitudo diatas yang memiliki periode ulang pendek berpotensi terjadi di wilayah lengan utara seperti Tolitoli, Gorontalo, Kotamobagu hingga Bitung. Wilayah yang memiliki periode ulang pendek adalah wilayah yang mempunyai aktivitas kegempaan yang tinggi, artinya bahwa gempa di wilayah ini umumnya di dominasi gempa bermagnitudo kecil sampai sedang.Sehingga dengan mengetahui wilayah-wilayah yang memiliki periode pendek ini sehingga dapat diwaspadai dari ancaman gempa bumi sedang samapai besar. 


\section{Kesimpulan}

Dari hasil analisis perubahan nilai parameter seismotektonik untuk wilayah Pulau Sulawesi dapat disimpulkan sebagai berikut:

1. Wilayah Sulawesi dan sekitarnya perubahan nilai parameter berkisar antara 0.55- 2.55, ini mengindikasikan bahawa wilayah ini mempunyai aktivitas tektonik yang cukup tinggi

2. Dari perhitungan dan plot perubahan nilai parameter seismotektonik dapat ditunjukkan bahwa nilai perubahan parameter $a-b$ di Sulawesi bervariasi akan tetapi umumnya didominasi nilai b yang cukup rendah yang memungkinkan pada saat-saat mendatang akan terjadi gempa-gempa dengan magnitudo sedang sampai besar.

3. Dari perhitungan periode ulang gempa sangat bervariasi tergantung dari besar kecilnya magnitudo. Gempa-gempa merusak dengan magnitudo M6.5 kemungkinan akan terjadi sekitar 6-30 tahun, gempabermagnitudo 7 memiliki periode ulang 14-70 tahun dangempa dengan magniutdo 7.5 memiliki periode ulang 36-162 tahun.

\section{Daftar Pustaka}

Gardner, J.K. and Knopoff, L. 1974. Is the sequence of earthquakes in southern California, with after socks removed, Poissonian?, Bulletin of the Seismological Society of America, 64: 13631367.

Gutenberg, B. and Richter, C. F. 1954. Seismicity of the Earth and associated phenomena, Second Ed., Princeton U Press, Princeton, New Jersey, 310.
Hall, R. and Wilson, M.E.J. 2000. Neogene Sutures in Eastern Indonesia, Journal of Asian Earth Sciences, 18: 781-808.

Pasau, G dan Tanauma. 2015. Analisis Resiko Gempa Bumi Lengan Utara Sulawesi Menggunakan Data Resolusi Tinggi Sebagai Upaya Mitigasi Bencana, Jurnal Spektra16(3): 610.

Pasau, G., Tamuntuan, G., Tanauma, A. 2016. Respons Sektra Gempa Bumi Lengan Utara Sulawesi Sebagai Upaya Mitigasi Bencana. Prosiding Seminar Nasional Geofisika; Makassar, 6 Agustus 2016.Program Studi Geofisika UNHAS. HIm 26-29.

Rohadi, S. 2015. Distribusi Spasial Dan Temporal Parameter Seismotektonik Sebagai Indikasi Tingkat Aktivitas Kegempaan di Wilayah Papua. Jurnal Meteorologi dan Geofisika16(3): 189198.

Stein, S. dan Wysession, M. 2003. An Introduction to seismology, earthquake, and earth structure, Blackwell Publishing Ltd, United Kingdom.

Utsu, T. 1965. A Method in Determining the value of $\mathrm{b}$ in a formula $\log \mathrm{N}=\mathrm{a}-\mathrm{bM}$ Showing the magnitude frequency for earthquakes. Geophysics Bull. Hokkaido Univ. 13: 99-103

Wandono., Widyantoro, S., Ibrahim, G., Soewono, E. 2004. Analisa Hubungan Frekuensi-Magnitudo Gempa Bumi di Bali dan Sekitarnya. Jurnal Matematika dan Sains ITB Bandung 9(3): 273277

Wiemer, S. 2001. A Software Package to Analyze Seismicity: ZMAP. Seismological Research Letters72:373-382. 